\title{
Consecuencias de la regularización de trabajadores extranjeros: 1991-1992
}

\author{
A. Izquierdo Escribano \\ Universidad Complutense. Departamento de Sociologla II \\ Campus de Somosaguas. 28023 Madrid. Spain
}

\section{Resumen}

La regularización de trabajadores extranjeros de 1991 ha modificado profundamente la composición demográfica y social de los inmigrantes en España, pero este cambio sustancial aún no se ha reflejado con claridad en la política del gobierno ni en las actitudes de los españoles.

Palabras clave: demografía de la inmigración, política de integración, actitudes hacia los inmigrantes, regularización de trabajadores extranjeros.

Abstract. Consequences of the foreigners' regularization: 1991.1992

The process of regularization of foreign workers in 1991 has changed the demographic and social composition of immigrants in Spain. More over this important change has not been reflected neither in a government policy of migration nor in Spanish people artitudes.

Key words: immigrants' demography, integration policy, attitudes towards immigrants, foreigners' regulatization.

\section{Sumario}

1. Primeta consecuencia: fin del predominio comunitario y de una inmigración atípica

2. Segunda consecuencia; crecimiento espectacular de los trabajadores no comunitarios y aproximación a la inmigración probable
3. Tercera consecuencia: euna política activa o una declaración política?

4. Cuarta consecuencia: capacidad de aco* gida y política de integración

5. Bibliografía 
La inmigración de trabajadores y familiares procedentes de "países terceros" es, desde el punto de vista sociológico, el fenómeno sociodemográfico que revela con más claridad las contradicciones internas e internacionales de la sociedad española en los últimos años del siglo XX. La transición de España como país de emigración hasta convertirse en uno receptor de inmigrantes se ha cubierto en menos de una década, y el núcleo de esa transformación hay que situarlo entre 1985 y 1991 .

En esas dos fechas ven la luz respectivamente la «Ley orgánica sobre derechos y libertades de los extranjeros en España" y la comunicación del gobierno al Congreso de los Diputados titulada "Líneas básicas de la política española de extranjería». De la primera, conocida como Ley de Extranjería, se desprendió una regularización colectiva de los extranjeros insuficientemente documentados. La segunda dio Lugar a la aprobación el 13 de marzo de 1991 de una proposición no de ley del Congreso de los Diputados. En esa proposición se solicitaba al Gobierno, entre otras medidas, la «legalización de los colectivos extranjeros que trabajan en situación irregular». En resumen, dos procesos de regularización que, en mi opinión, han tenido tuna influencia sustancial en la configuración de España como país de inmigración.

Es necesario definir con claridad esa caracterización de sociedad que recibe inmigrantes, toda vez que aún, en 1993, salen españoles a trabajar temporalmente a otros países y en un goteo más callado algunos también marchan para instalarse de forma duradera, a veces definitiva. Esa conjunción cual es la de ser a un tiempo pás de emigración y de inmigración, es una realidad en varios países europeos y, aún más, un rasgo importante e insuficientemente destacado de nuestra época. Sin embargo, desde mediados de la década de los setenta, son más numerosos los extranjeros que entran con el propósito de establecerse en España que los españoles que salen con igual objetivo. El saldo migratorio ha cambiado su signo y, ahora, es positivo. Este sería, desde el lado puramente demográfico, el indicador del cambio.

Pero hay otros datos que, sociológicamente, tienen más relevancia. En primer lugar está el flujo de trabajadores no comunitarios que llegan con la intención manifiesta de quedarse definitivamente. En segundo lugar, la corriente de familiares que, con ligero retraso, sigue a los primeros. En tercer lugar, la declarada, aunque titubeante, política activa del Gobierno español. Y, por último, la progresiva aunque contradictoria asimilación por parte de la opinión pública española de que nos hemos convertido en un país de inmigración.

Sin duda, hay otros hechos significativos, que llevan a la misma conclusión, pero me voy a limitar a los anteriores porque ellos son, principalmente, una consecuencia directa de la regularización de 1991.

\section{Primera consecuencia: fin del predominio comunitario y de una inmigración atípica}

No es lo mismo inmigrante que extranjero. Aquf vamos a tratar siempre de los extranjeros (personas cuya nacionalidad no es la española), aunque por ali- 
gerar la lectura se utilizan, sin mayores precisiones, una y otra palabra. Tampoco es lo mismo migración (movimiento) que migrante (persona), pero en este breve artículo voy a poner las ideas por encima de los conceptos controvertidos, todo hay que decirlo, en el ámbito de la investigación de las migraciones internacionales. Quiero destacar en este epígrafe el discurrir numérico, a tenor de los registros oficiales, de los extranjeros instalados legalmente en España (tabla 1).

Tabla 1. Distribución del stock de residencias en vigor al 31-XII de los años 1989 a 1992.

\begin{tabular}{llllll}
\hline Año & R. general & $\%$ & R. comunitario & $\%$ & Total \\
\hline 1989 & 123.902 & 49,7 & 125.657 & 50,3 & 249.559 \\
1990 & 137.589 & 49,4 & 141.207 & 50,6 & 278.796 \\
1991 & 216.770 & 60,1 & 143.885 & 39,9 & 360.655 \\
1992 & 213.742 & 54,4 & 179.358 & 45,6 & 393.100 \\
\hline
\end{tabular}

Fuente: D.G.P. Memorias anuales. Ministerio del Interior.

En los últimos dos años se ha producido un aumento espectacular debido a la legalización de 109.000 trabajadores y 7.000 familiares. El primer dato (los más de cien mil trabajadores no comunitarios) se refleja en el aumento entre 1990 y 1991 de los permisos de residencia concedidos dentro del régimen general. El descenso absoluto, y sobre todo en términos relativos en 1992, del stock de residencias en ese régimen, se debe a que no todos los regularizados han renovado su permiso. Aún no hay datos concluyentes del proceso de renovación, pero es probable que al menos una cuarta parte del total no lo haga. Hipotéticamente unos habrán emprendido el retorno, otros se habrán marchado hacia paises distintos y probablemente, un grupo bien nutrido de los legalizados, haya recaído en la irregularidad.

Hasta 1991 España era, oficialmente, un país con una inmigración compuesta en su mayoría por extranjeros provenientes de los paises de la Comunidad Europea y en primer lugar de Gran Bretaña. Las características más notorias del conjunto de la población foránea eran: su reducida tasa de actividad laboral, un bajo índice de masculinidad y un envejecimiento notable. Para coronar esa sorprendente uinmigración", la proporción de solteros apenas rebasaba un tercio del total. Lo diré en cifras de finales de 1990: un 58\% de extranjeros estaban casados, el $51 \%$ del total eran mujeres, el $13 \%$ tenían más de 60 años y más del $60 \%$ procedían de la Europa comunitaria.

Pues bien, a finales de 1992, tras el definitivo impacto de la regularización la distribución de la población extranjera según nacionalidad y áreas continentales ha experimentado una modificación profunda (tabla 2).

Menos de la mitad de los extranjeros con permiso de residencia son de origen comunitario y el primer país por el número de inmigrantes es Marruecos. Los I 16.000 regularizados de origen extracomunitario también han trastoca- 
Tabla 2.

\begin{tabular}{lcr}
\hline Área continental & Núm. absolutos & $\%$ \\
\hline Europa & 196.972 & 50,1 \\
América del norte & 15.237 & 3,9 \\
América del sur y central & 74.063 & 18,8 \\
África & 71.293 & 18,1 \\
Asia & 33.879 & 8,6 \\
Oceanía & 747 & 0,2 \\
Apátridas & 909 & 0,2 \\
\hline Total & 393.087 & 0,2 \\
\hline
\end{tabular}

Fuente: D.G.P. Memoria 1992.

do hondamente la composición demográfica de la inmigración en España. En efecto se ha rebajado la proporción de casados, de personas en edad no activa y de mujeres. En suma, se trata de una población más joven y con más trabajadores extracomunitarios.

2. Segunda consecuencia: crecimiento espectacular de los trabajadores no comunitarios y aproximación a la inmigración probable

La regularización colectiva de 1991 no sólo ha legalizado la situacion de los trabajadores indocumentados, sino que también ha "normalizado", por así decirlo, la inmigración. No eran unormales" en un período de intenso crecimiento económico (1986-1991) la escasez de trabajadores y muy particularmente de la mano de obra de origen no comunitario (tabla 3 ).

Ciertamente, la regularización ha incrementado la proporción de trabajadores en el conjunto de la inmigración desde un $28 \%$ en 1989 hasta un $47 \%$ en 1991 y alrededor de un $45 \%$ a finales de 1992 si tuviéramos en cuenta a los trabajadores que proceden de la CE. Junto al incremento del peso de los trabajadores extranjeros se ha intensificado la presencia de mano de obra procedente del Tercer Mundo. En cuatro años el volumen de trabajadores de países terceros se ha triplicado sobradamente.

Tabla 3.

\begin{tabular}{lccc}
\hline & $(1)$ & $\begin{array}{l}\text { (2) Trabajadores } \\
\text { no comunitarios }\end{array}$ & $\begin{array}{l}(2):(1) \\
\%\end{array}$ \\
\hline 1989 & Total trabajadores & 40.233 & 58,3 \\
1990 & 69.034 & 50.168 & 58,9 \\
1991 & 85.238 & 124.554 & 72,8 \\
$1992^{*}$ & 171.033 & 139.695 & - \\
\hline
\end{tabular}

Fuente: Permisos de trabajos a extranjeros Ministerio de Trabajo y Seguridad Social.

* En el stock al 31-XII-1992 ya no se incluyen los comunitarios. 
También eran poco usuales los rasgos demográficos y ocupacionales de los trabajadores extranjeros en España antes de la regularización de 1991. Una mưy elevada feminización de la fuerza de trabajo $(35 \%)$, endeble presencia de menores de 25 años (13\%) y ridícula participacion de los trabajadores en la agricultura y en la construcción. Por no hablar de la sobrerepresentación de técnicos y profesionales $(23 \%)$ y en general de los trabajadores muy cualificados.

Después de la regularización el perfil socio-laboral se ha visto rejuvenecido y masculinizado. A la par que la agricultura, la construcción y los servicios menos cualificados (en particular el servicio doméstico y de limpieza en cafeterias, hoteles y restaurantes) se constituyen en las actividades y ocupaciones con más población foránea.

A esta notable modificacion del stock de trabajadores le ha seguido la regularización de 7.000 familiares de los trabajadores legalizados. De modo que se ha iniciado el ciclo del reagrupamiento familiar que, previsiblemente, se dará con cierto retraso hasta que el trabajador consolide su estabilidad legal y laboral con un permiso de duración superior a un año y una experiencia de trabajo continuado dentro de la eventualidad. Más claramente el reagrupamiento familiar proseguirá con la renovación del primer permiso de trabajo y, aún más, con el cambio a un tipo de permiso de duración quinquenal. La estabilidad laboral no significa conseguir un contrato como trabajador fijo, sino trabajar con cierta continuidad aunque sea con frecuentes cambios de patrono y de sector de actividad.

Estas consecuencias de la regularización suponen un giro sustancial en la dirección de la inmigración más probable, aunque no sea la preferida por la opinión pública. Pero esta vía hacia el realismo en materia migratoria puede verse facilitada u obstaculizada por la política que se practique desde los poderes públicos.

\section{Tercera consecuencia: ¿una política activa o una declaración política?}

El Gobierno del Partido Socialista ha fijado un contingente de trabajadores extranjeros para 1993. Esa medida era La primera que se destacaba en la ya cirada proposición no de ley de marzo de 1991. Su propósito es el de canalizar y organizar los flujos de inmigración laboral en función de las necesidades de mano de obra de la economía española y de la capacidad de absorción de la sociedad. Eso significa que hay ofertas de empleo no cubiertas por los españoles desempleados.

El cupo se ha cuantificado sobre las siguientes bases empíricas: ofertas de empleo pendientes (46.000 en 1991) y ocupaciones donde se ha producido un mayor número de trabajadores regularizados. El resultado de seguir estos dos caminos ha sido el de determinar un contingente de 20.600 trabajadores repartidos entre las actividades agrícolas $(10.000)$, el servicio doméstico $(9.500)$ y la construcción (1.100). No ha lugar aquí una crítica de los fundamentos técnicos seguidos para fijar esa cifra. Se trata de una medida política y como tal debe tomarse. 
La cuestión es cómo se organiza esa política interna e internacionalmente. Brevemente, cual es el papel de las organizaciones empresariales y sindicales (principalmente) a la hora de solicitar, transportar, acoger $e$ instalar a esos trabajadores. En el otro cabo de la cuerda está la decisión de con qué países se ha de articular el contingente de mano de obra, cómo realizarlo y qué contrapartidas se esperan.

Los asuntos que hay que tener previstos no son pocos. Tomemos la agricultura como ejemplo. Se trata, en su mayoría, de una demanda de trabajadores para faenas que no se prolongan más allá de algunas semanas o meses. Una gran parte de las explotaciones agrícolas son de tamaño teducido y requieren pocos trabajadores. Estos pequeños empresarios, por lo general, no están en condiciones de formular una petición concreta con la suficiente antelación y no aceptan correr con los gastos de viaje y el alojamiento de estos trabajadores eventuales. Los sindicatos no llegan a organizar a estos trabajadores temporeros y desconfian de la concurrencia respecto de los autóctonos. Así, los empresarios se quejan porque los españoles no acuden a la oferta de empleo y los sindicatos se lamentan del escaso control que se tiene sobre la contratación irregular y, en su caso, de la competencia desleal de los trabajadores extranjeros.

Como se ve no es fácil cumplir con el objetivo del contingente y no es seguro que no lleve aparejado un aumento de la inmigración irregular. De modo que hay que evaluar su grado de cumplimiento y su eficacia a la hora de aminorar el flujo de indocumentados. Más aún, hay que explicar a la opinión pública esa política y en el futuro habrá que mantenerla o enmendarla con razones probadas.

\section{Cuarta consecuencia: capacidad de acogida y política de integración}

¿Cómo medir la capacidad de acogida de una sociedad? La noción de umbral de tolerancia es pura ideología, esto es, falsa consciencia de la realidad. El hecho es que la capacidad de acogida es un segundo eje de la política activa de inmigración. He adelantado que la opinión pública española va percibiendo, aunque sea de manera insuficiente y contradictoria, el escenario mas probable, a saber: que una proporción importante de los que llegan a España tienen la intención de establecerse definitivamente.

El Gobierno así lo reconoce cuando segmenta el contingente, mitad por mitad, entre inmigrantes temporales y otros con carácter permanente. Sólo que no ha formulado una política explícita de integración. No hay criterios, ni medidas concretas. No se sabe si son los ayuntamientos los puntales de la política de integración, ni existe acuerdo, en la práctica, sobre si son los servicios comunitarios o los especializados los que van a lievar el peso de la tarea. $\mathrm{Y}$ aśí, unos apuestan por la atención especializada y por la práctica multicultural, mientras que otros se decantan por la intervención de carácter comunitario en igualdad con los autóctonos o, para decirlo sin matices, están a favor de una acción que promueva la homogeneidad social y cultural. La carencia de un 
proyecto de integración se puede ver con claridad en la propuesta del cupo a saber y, por poner un ejemplo: no hay ni una línea dedicada a pensar en el alojamiento provisional o definitivo de los veinte mil trabajadores temporales o permanentes.

Dos datos, en el plano de las actitudes globales, pueden contribuir a situar la nebulosa cuestión de cuál sea, en 1993, la capacidad de acogida de los españoles. Uno es que el $60 \%$ de los inmigrantes regularizados en 1991 declara que no tiene la intención de volver, algún día, a vivir definitivamente a su país. Dos, el 46 por cienro de los españoles cree que tienen la intención de permanecer aquí por un tiempo y luego regresar a su país de origen y, lo que es más importante, prefieren que vengan una temporada, sin familiares y luego retornen. En pocas palabras, la mayoría de los inmigrantes piensa en instalarse definitivamente, mientras que poco más de un tercio de los españoles está dispuesto para afrontar esta nueva realidad. Habrá que insistir en este punto y adecuar los planes de los inmigrantes y las preferencias de los autóctonos para que la regularización no tenga como consecuencia no querida un aumento de la discriminación.

\section{Bibliografía}

ARAGON BOMBIN, R. Projet de programmation des flux migratoires et systeme de quotas en Espagne. Documento presentado en la conferencia organizada por la OCDE, Canadá y España, en Madrid, 29-31 marzo de 1993.

CIRES. Actitudes hacia los inmigrantes. Boletín de marzo de 1993.

CIS. Estudio, 2051. Marzo 1993.

IZQUIRRDO ESCRIBANO, A. (1993). «Política e inmigración en la España de 1992». En Inmigracion, pluralismo y tolerancia. Madrid: Editorial Popular, p. 87-124.

- (1992). "La inmigración inesperada". Mientras tanto, núm. 49, marzo-abril, p. $85-105$.

- (1992). La inmigración en España 1980-1990. Ministerio de Trabajo y Seguridad Social, p. 260.

MOUEIER BOUting, Y.; GARSON, J-P. y SIlberman, R. (1986). Economie politique des migrations clandestines de main-d'oeuvre. París: Publisud, p. 276.

"Situación de los extranjeros en España. Líneas básicas de la política española de extranjerian. Economia y Sociologia del Trabajo, núm. 11, marzo de 1991.

SOPEMI 1989 Analyse comparative des recentes experiencies de regularisation en France, Italie, Espagne et aux Etats Unis. París 1990. 